\title{
sciendo
}

\section{Innovation capability assessment tools in social enterprises}

\author{
Ruxandra ARGATU \\ Bucharest University of Economic Studies, Bucharest, Romania \\ argatu.ruxandra@gmail.com
}

\begin{abstract}
Innovation is among the pursuits of any modern organization nowadays, constituting the core of collective progress and of competitive advantage. The global rising tendency in competitiveness urges companies, public institutions and other community actors to adhere to this naturally evolutionary pattern that occurs in any kind of system. To achieve welfare in a context of continuous changes, an organization has to make sure that its processes are perfectly aligned to its mission. Additionally, having a clear picture on its innovation capability, meaning the ability of producing a valuable output by transforming internal collective knowledge, enables it to follow the road to success. In the case of traditional enterprises, which pursue profit accumulation, evaluating the innovation capability is done on the basis of clearly defined instruments, but when referring to social enterprises, a variety of factors come in place and make the evaluation more difficult. The scarce current research done concerning the assessment of innovation capability for social enterprises makes this topic meaningful to be explored, so their societal purpose can be better delivered. Thus, the aim of the paper is to formulate a framework for determining the innovation capability of Romanian social enterprises by building on the good practices reflected by innovation projects in the social field, funded through the Horizon 2020 programme at EU scale. The research methodology resides on two pillars. In the first place, it contains literature review on the concepts of innovation, social innovation, innovation capability and the instruments used to assess it. Secondly, it brings together the exemplary undertakings of multiple social innovation projects delivered through the Horizon 2020 programme and concentrated into online reports, accessible through its website.
\end{abstract}

Keywords: innovation, innovation capability, social innovation, innovation assessment, tools, social enterprises, Romania.

\section{Introduction}

Attaining business welfare, in general, and societal wellbeing, in particular, is subject to diversified factors of influence, but maybe the most appropriate one to the present global environment is innovation. Rebuilding existing structures or even creating new and powerful ones when needed is mandatory for economic growth and community empowerment, in equal terms, hence for enabling transformational grounds. There has been a strong concern expressed by researchers with respect to comprehending organizations' reactions to the innovativeness demand (Bellini et al., 2019; Björkdahl \& Börjesson, 2012). As per Fred-Ojala et al. (2018), innovation constitutes a critical determinant that leads the way to human advancement, positive alleviations of markets as well as the issuance of discoveries in the technological domain. Providing insights on the organizational field, McKinsey illustrates through a survey the fact that the elements that accelerate innovation at organizational scale are the human resources and the culture of the company, as agreed by $70 \%$ of executive managers and $94 \%$ of senior executive managers.

In essence, there are not consistent dissimilarities between delivering innovation in the case of traditional organizations and the entities that act in the benefit of various societal groups of a certain community, meaning social enterprises. The main differentiation point resides in the 
beneficiary of the innovation created, which, for a traditional enterprise is represented by its stakeholders, namely those parties that can influence the company's objectives and future conduct. Here we may distinguish between primary stakeholders, such as customers, suppliers, personnel, and secondary stakeholders, for instance competition, the government and groups of interest at public level (Matuleviciene \& Stravinskiene, 2015). The beneficiary of a social enterprise can be directly derived from the definition of the social entrepreneur provided by Mosher-Williams (2006): a person who follows, despite obstacles faced, a groundbreaking idea meant to address the problems of society in a manner that transforms the foundational structures in which the issues are originated. Thus, we may claim based on this, that the beneficiaries are the members of the social enterprises' local community, that reap the advantages of the innovations delivered to them.

Addressing the right kind of organizational innovation or social innovation is only the first step towards competitiveness. However, issues may arise when establishing and measuring an enterprise's innovation capability. Innovation and the process of knowledge scattering have produced a kinetic effect upon the frontiers of an organization, as according to Oliveira and Trento (2018). Hence, evaluating the innovation capability, namely the potential to take advantages of the opportunities arising, nurture novel know-how and employ existing assets in this respect (Benaim, 2015), has become a much more troublesome process as circumstances changed. Despite the wide acknowledgment of innovation capabilities' importance, Rådesjö and Sandström (2013) claim that a great number of organizations do not present the inner ability to tackle opportunities and to be flexible against changes.

Measuring the innovation capability of social enterprises is also justified by the relatively limited research existing at the current point, since most of the researchers' efforts are concentrated upon the traditional enterprise model and innovativeness. Due to this, the purpose of the paper is to study the current innovation capability assessment methods emphasized by literature and the lessons to be learnt from Horizon 2020 programmes accomplished in the European Union and based on that, to develop a new possible model through which such capabilities can be evaluated for social enterprises in Romania.

\section{Literature review}

\section{Views on innovation and social innovation}

The term innovation captures an umbrella of meanings but in a general sense it implies the reliance on creativity to bring out of the box ideas or to deliver improvements to business processes, as well as being in an explorative pursuit (Fred-Ojala et al., 2018). Innovation is the primary point that organizations need to refer to if they wish to increase their effectiveness and be highly responsive to competition (Rumanti et al., 2018). According to Benaim (2015), innovation is a component producing effects in miscellaneous areas of an organization: networks, procedures, product efficiency, involvement of customers and channels of communication.

To facilitate innovation, knowledge sharing at the organizational level is recommended and can be done by direct interaction between employees through practices such as mentoring and switching employees' roles in the overall system ((Moh'd Taisir) Masa'deh et al., 2015). Fostering and accelerating innovation as a game changing factor, no matter the field, can be reached also through persevering $\mathrm{R} \& \mathrm{D}$ efforts. There is an encouraging positive interdependence between R\&D and innovation, on one hand, and R\&D and economic prosperity, on the other hand (Akcali \& Sismanoglu, 2015). Research performed by Preda (2013) adds organizational learning to the multitude of determinants helping innovation to flourish and defines it as a 
method of creating knowledge. Economic and societal-purpose entities can perform learning processes either at internal level, relying on their own knowledge, or at the external scale, case in which they capture outer knowledge and incorporate it in their practices (Jiménez-Jiménez \& Sanz-Valle, 2011).

Innovation at organizational and community level impose complementarity, as the nowadays problems raising in the social field are closely bonded, they have an integrative aspect when speaking about their result, they are durable in time and also unpredictable (Schuitmaker, 2012). Social innovation thus comes as a relevant helping tool in empowering communities, being a kind of innovation that follows a societal aim in what regards its ending point and its method, by rendering citizen entitlement and community change (Avelino et al., 2019). Entities providing prizes in social entrepreneurship seek certain attributes of social innovation, such as the delivery of novel ideas and a vision anchored in reality that creates systemic rearrangements by using a distinctive way of action (Poon, 2011).

Justified by its high degree of expressiveness, concern for innovation is manifested at societal level in the EU, through the creation of social innovation institutes of research: Netherlands and Austria - Centre for Social Innovation, and social innovation programs, such as TEPSIE - The Theoretical, Empirical and Policy Foundations for Building Social Innovation in Europe (Kocziszky \& Somosi, 2016).

The production of positive and innovative changes within communities can thus be reached through multi-stakeholder partnerships, as the problems of the world cannot be resolved by one economic or social structure so it is necessary for governments, traditional enterprises and NGOs to exchange knowledge (MacDonald et al., 2019). Further reasons for this form of collaboration are the division of risk and making use of capabilities or resources that are not in their current property (Paixão Garcez et al., 2014) as well as creating a synergic result and attaining operational resilience (Reficco et al., 2018).

As a participant of multi-stakeholder partnerships, social enterprises have a catalytic role in setting social innovation in motion, by employing their human and financial assets to create societal improvement (Testi et al., 2019). Countries from the European Union experience difficulties in minimizing social polarization and variations and for this to be lowered, both profit-oriented and non-profit oriented organizations need to act together (Andries et al., 2019).

Regarding the situation of social entrepreneurship in Romania, Ashoka (2019), the most developed social innovation network worldwide, conducted a survey on its stakeholders to understand the most pressing issues of Romania. The respondents have mostly pointed out the social mindset, the obsolete educational system, poverty, social exclusion of marginalized groups and the absence of NGO assistance. Thus, the main point of the research was that sustained effort needs to be employed for helping social enterprises perform adequately: workshops, social entrepreneurial education programs and the creation of such social networks. Other best practices identified by Mitra-Crisan et al. (2015) for Romanian social enterprises refer to embodying the beneficiaries of social enterprises within the actions taken for helping them, reducing legislative obstacles and inadequate managerial practices. Additionally, Păunescu et al. (2018) agree that entrepreneurial pursuits are correlated with the social balance of a country.

\section{Innovation capability and assessment instruments}

Developing and sustaining innovation cannot be possible without owning innovation capabilities. Research of Rodriguez et al. (2014) reveals a pronounced current shortage of alternatives by which companies quantify organizational innovation capabilities and as such, competitiveness 
and social progress are slowed down. Additionally, Björkdahl and Börjesson (2012) state that besides the scarcity of appropriate measurement instruments, organizations also find it difficult to strengthen their capabilities because of certain impeding factors, such as their thinking approach, absence of inventiveness, improper foreseeing and infrastructural impediments.

According to Wallin et al. (2011), innovation capabilities imply proficiency in reaching an innovative output, and in order for companies to properly manage such processes, it is mandatory for them to employ recovery methods for boosting these skills. Haryani and Gupta (2016) reinforce these findings and refer to interdepartmental collaboration, through which innovation-associated risks are diminished, the focus on customers by decoding their demands and providing them solutions of excellence, and market rivals' orientation, namely evaluating their actions and delivering a practical reaction.

The careful assessment of an enterprise's innovation capability is an intricate process since there are several points to be consulted (Haryani \& Gupta, 2016), this procedure enabling companies to determine their degree of goal achievement and further actions to be initiated (Grillo et al., 2018) and to create a system of learning by doing (Benaim, 2015).

The study of Oliveira and Trento (2018) presents a model of assessing innovation capabilities which is comprehensive as it does not include only organizational resources and experience. In this model leadership is also addressed, namely the leader's concern towards innovation, the steps taken to foster it, exemplified by encouragement methods and innovation incubators, and to communicate innovation objectives within the organization.

Following a highly structural approach, Rodriguez et al. (2014) provide a model that includes the innovation process and the organizational level at which it occurs, namely individual or company-wide, the path followed by it - upward or downward, and its origin - result of an internal knowledge and competencies or facilitated by a market opportunity. The model also integrates the innovation outcome: its type - product or process innovation, its designation company, market or industry, its scale - gradual or radical, and its essence - tacit or explicit. By difference, Purwanggono and Amalia (2019) do not consider only the results of innovation and the paths to achieve them, but also the leadership needed, translated into values, mission and vision; the organizational culture, defined through the existing trust level and the risk reactions; the innovation action plan, the resources and partnerships embedded; the integration of customers' fulfillment and employees' meaningful involvement.

Last but not least, the assessment framework proposed by Björkdahl and Börjesson (2012) emphasizes the innovation strategy as a reflector of innovation capabilities, through the level at which it is comprehended by organizational members and benchmarked against competition, the ranking of innovation projects based on their importance and the assistance provided by top management despite a considerable risk probability, as well as the decisional systems and guidelines for resource allocation.

\section{Methodology}

Relying on the literature review analysis performed, the paper proposes to construct a model for evaluating the innovation capabilities of social enterprises in Romania, by also integrating the lessons to be learnt by these entities from the various Horizon 2020 programs on social innovation in the EU. Thus, the first part of the methodology concentrates a document analysis on three social innovation projects carried out under the Horizon 2020 umbrella and further on, it 
provides an innovation capability assessment framework for social enterprises activating in Romania. The project selection criterion was a temporal one, as the findings of the programs producing tangible results in the last five years were explored.

According to Pollex and Lenschow (2018), Horizon 2020 is a program that offers research funding and which creates a paradigm shift in $\mathrm{R} \& \mathrm{D}$ practices since it recognizes its essential impact on the progress of the European Union. When speaking about the quantification of the funding provided by the program, the European Commission (2014) indicates the availability of approximately 80 billion Euro, this sum being allocated on a time span of 7 years, starting with 2014 and ending with 2020.

\section{Results and discussions}

\section{Document analysis on Horizon 2020 social innovation projects}

The first section of the methodology embodies a systematic review of 3 existing projects on social innovation implemented through Horizon 2020, as per Table 1, in order to identify good practices that can be shared by social enterprises in Romania for developing and appraising innovation capabilities.

Table 1. Horizon 2020 social innovation projects

\begin{tabular}{|c|c|}
\hline $\begin{array}{c}\text { Project name and } \\
\text { vulnerable group targeted }\end{array}$ & Results and lessons to be learnt \\
\hline $\begin{array}{l}\text { SIMRA - Social Innovation } \\
\text { in Marginalized Rural Areas } \\
\text { (people inhabiting } \\
\text { marginalized rural areas) }\end{array}$ & $\begin{array}{l}\text {-creating a framework for understanding time changes in social } \\
\text { innovations through pinpointing the determinants altering social } \\
\text { innovators' actions } \\
\text {-establishing the variables that impacted the identified social } \\
\text { innovations in rural areas } \\
\text {-utilization of customizable tools (focus groups, interviews) for } \\
\text { tracking social innovation consequences } \\
\text {-anchoring on institutional, social and economic attributes generated } \\
\text { (development of social capital, generating new business possibilities) } \\
\text {-employing social media tools for centralizing stakeholder } \\
\text { collaboration (hubs and incubators) } \\
\text {-transmission of findings to the relevant parties: policy-creating } \\
\text { authorities, social innovation alliances, European Union bodies } \\
\text {-delivering operational support to social enterprises } \\
\text {-conducting recurrent meetings to explore the steps to be taken }\end{array}$ \\
\hline $\begin{array}{l}\text { Except Project } \\
\text { (young people facing } \\
\text { unemployment) }\end{array}$ & $\begin{array}{l}\text { Findings at the Romanian scale: } \\
\text {-the main groups at risk are young people with inexistent, reduced or } \\
\text { obsolete capabilities, those who inhabit vulnerable regions, have left } \\
\text { school early or present disabilities } \\
\text {-in terms of results, the policies managed to deliver technical } \\
\text { qualification of machine workers to the beneficiaries of vocational } \\
\text { courses, to collaborate with providers of social services and to } \\
\text { customize the employment help to each NEET individual, and to } \\
\text { provide grants to employers that hired people having an } \\
\text { apprenticeship in their companies. } \\
\text { Lessons learnt: } \\
\text {-understanding the status of young people regarding poverty and } \\
\text { social exclusion and the impact of employment uncertainty } \\
\text {-establishing the social and economic consequences of the youth } \\
\text { inclusion programs, in the short and long-run }\end{array}$ \\
\hline
\end{tabular}




\begin{tabular}{|l|l|}
\hline & $\begin{array}{l}\text {-drawing a warning sign on the issues of the Romanian educational } \\
\text { system }\end{array}$ \\
\hline $\begin{array}{l}\text { ImPRovE (Poverty, Social } \\
\text { Policy and Innovation) } \\
\text { (people affected by poverty) }\end{array}$ & $\begin{array}{l}\text {-setting the grounds for the positive modification of EU policies } \\
\text {-determining the influence of policy-prevention tools upon facing } \\
\text { income-associated poverty (child allowances, minimum levels of the } \\
\text { income tax and the bottom level of wages) } \\
\\
\text {-strengthening the social aid provided to poor people appears to be } \\
\text { the most efficient policy from the financial point of view }\end{array}$ \\
\hline
\end{tabular}

Source: SIMRA (2019), Except Project (2019), Pantea (2018), ImPRovE (2012),

Cantillon et al. (2015), Leventi et al. (2016)

\section{Development of an innovation capability assessment framework for Romanian social enterprises}

Based on the performed summary analysis of 3 Horizon 2020 projects on social innovation, we suggest that social enterprises from Romania as well as the other actors involved in the social endeavor firstly need to understand which are the variables impacting the activities focused on creating social value. Additionally, they thoroughly need to have an accurate picture on the performance and efficiency degree of socially-oriented tasks and to be properly able to engage any relevant community actors in improving the value delivered. In order for the innovation capabilities to be fully supported and implemented, social enterprises also have to communicate the results identified through their best practices to responsible authorities so people facing poverty or other misfortunate social contingencies can be timely protected.

Due to these observations, we propose the following model for evaluating the innovation capability of Romanian social enterprises, which forms a closed loop as according to Figure 2.

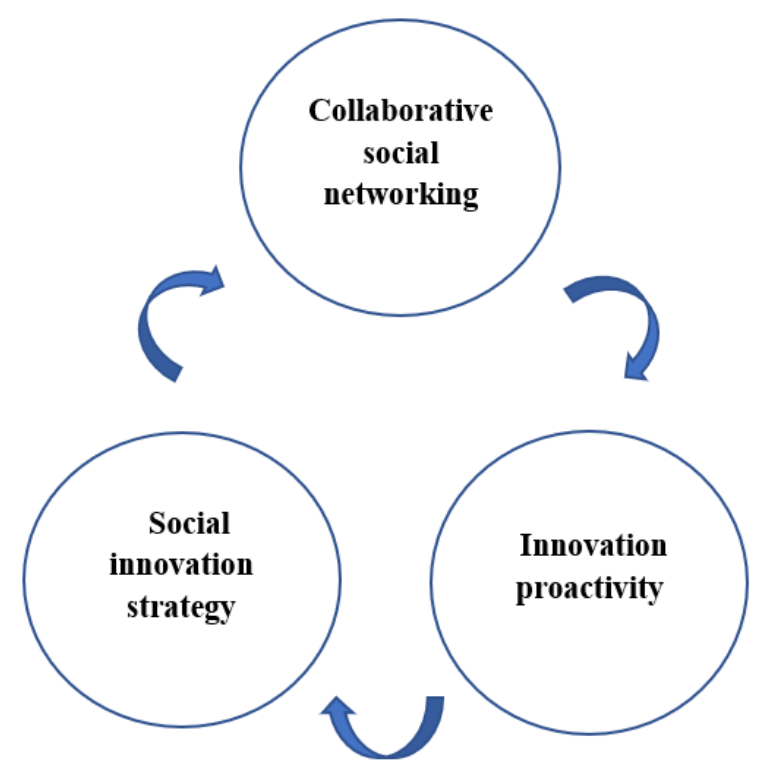

Figure 2. A model for assessing the innovation capabilities of Romanian social enterprises

Source: Author's own research

The proposed model, illustrated in Table 2, encompasses 3 primary dimensions: collaborative social networking, innovation proactivity and social innovation strategy.

Analyzing the specific intent of each dimension, we may state that the first dimension, collaborative social networking, aims to determine how capable the social enterprise is in 
effectively managing and empowering the networks created with public and private community actors to create a win-win outcome for all participating parties and how it further utilizes the knowledge resulting from them. As for the innovation proactivity capabilities, they refer to how the organization systematizes innovation priorities and external influencing factors and how it correlates managerial practices with the resources employed, according to the social enterprise's profile and opportunities. Finally, the social innovation strategy dimension evaluates the social enterprise's understanding of the importance of evaluating the innovation results and defining clear and attainable objectives together with key performance indicators to track corresponding progress.

For quantifying the results of the model, each sub-component indicator is rated on a Likert scale from 1 to 5,1 corresponding to a strong disagreement and 5 being associated to a strong agreement. After grading the sub-components, every dimension receives an average score on the basis of the scores allocated to the sub-components that form it, being averaged at its turn.

Table 2. An innovation capability assessment framework for Romanian social enterprises

\begin{tabular}{|c|c|}
\hline $\begin{array}{c}\text { Dimensions and corresponding } \\
\text { explanations }\end{array}$ & Sub-component indicators \\
\hline $\begin{array}{l}\text { 1. Collaborative social } \\
\text { networking }\end{array}$ & \\
\hline $\begin{array}{l}\text { 1.1. Does the social enterprise } \\
\text { effectively manage the networks } \\
\text { formed with public and private } \\
\text { community actors? }\end{array}$ & $\begin{array}{l}\text { 1.1.1. The social enterprise engages in multi-stakeholder } \\
\text { partnerships and successfully exchanges social innovation practices, } \\
\text { knowledge and innovation capabilities with other social enterprises } \\
\text { and other community actors (universities, research centers focused } \\
\text { on social innovation). } \\
\text { 1.1.2. The social enterprise is thoroughly focused on integrating its } \\
\text { stakeholders within all its social innovation processes that it } \\
\text { performs by residing on instruments such as social innovation } \\
\text { incubators. } \\
\text { 1.1.3. The knowledge resulting from the partnerships with } \\
\text { community actors and enterprises is embedded in the culture of the } \\
\text { social enterprise. } \\
\text { 1.1.4. There is an in-built initiative of communicating in a clear } \\
\text { manner the undertaken social programs' results to the authorities that } \\
\text { have decisional role in shaping social matters at local and national } \\
\text { level and even organisms of the European Union. } \\
\text { 1.1.5. The social enterprise carries on periodic meetings with } \\
\text { decisional authorities to promote positive changes in legislation to } \\
\text { the benefit of threatened social groups. } \\
\text { 1.1.6. The social enterprise shows diligence in attracting the needed } \\
\text { public assistance for delivering innovative community resolutions, } \\
\text { both in financial and consultancy terms. }\end{array}$ \\
\hline \multicolumn{2}{|l|}{ 2.Innovation proactivity } \\
\hline $\begin{array}{l}\text { 2.1. Is there a permanent fo } \\
\text { on the end beneficiaries of } \\
\text { social enterprise's innovat }\end{array}$ & $\begin{array}{l}\text { 2.1.1. The social enterprise demonstrates commitment towards } \\
\text { understanding the needs of their beneficiaries and tailors the social } \\
\text { programs performed to their needs. }\end{array}$ \\
\hline
\end{tabular}




\begin{tabular}{|c|c|}
\hline quest? & $\begin{array}{l}\text { 2.1.2. The social entrepreneur recognizes the importance of } \\
\text { innovation activities and their ability of raising the social } \\
\text { competitiveness of the social enterprise and helping it to better fulfill } \\
\text { its societal purpose. }\end{array}$ \\
\hline $\begin{array}{l}\text { 2.2. Does the social enterprise } \\
\text { have a well-defined innovation } \\
\text { perspective adapted to external } \\
\text { circumstances? }\end{array}$ & $\begin{array}{l}\text { 2.2.1. Based on the identified societal opportunities and established } \\
\text { innovation objectives, the social enterprise issues an articulated } \\
\text { action scheme for innovation. } \\
\text { 2.2.2. The social enterprise has a } 360 \text {-degree outlook on external } \\
\text { conditions to identify the factors that direct innovativeness and its } \\
\text { temporal modifications. } \\
\text { 2.2.3. The social enterprise performs a systematic hierarchization of } \\
\text { social innovation programs according to their priority degree set by } \\
\text { external societal opportunities. }\end{array}$ \\
\hline $\begin{array}{l}\text { 2.3. Is the social entrepreneur } \\
\text { concerned with positively } \\
\text { altering the current innovative } \\
\text { output? }\end{array}$ & $\begin{array}{l}\text { 2.3.1. The social entrepreneur has a clear sense of the current } \\
\text { performance of the social enterprise and the innovation procedures } \\
\text { to be further embedded. Consequently, he allocates a part of the } \\
\text { organizational resources for R\&D activities. } \\
\text { 2.3.2. The best practices attained through the implemented actions, } \\
\text { either at institutional or societal level are used to foster new } \\
\text { directions of action. } \\
\text { 2.3.3. There is a particular attention placed on organizing meetings } \\
\text { with employees to establish the progress attained and the areas to be } \\
\text { improved. } \\
\text { 2.3.4. The managerial practices, the priorities of action and the } \\
\text { resources to be used are defined on the basis of the scope and } \\
\text { specificities of the social enterprise that the social entrepreneur runs. } \\
\text { 2.3.5. The social enterprise determines the factors which shape social } \\
\text { innovation. }\end{array}$ \\
\hline \multicolumn{2}{|l|}{ 3. Social innovation strategy } \\
\hline $\begin{array}{l}\text { 3.1. Does the social enterprise } \\
\text { establish indicators and tools } \\
\text { that reflect the innovation } \\
\text { progress? }\end{array}$ & $\begin{array}{l}\text { 3.1.1. The social enterprise is open towards the utilization of } \\
\text { quantitative and qualitative tools, namely questionnaires, interviews } \\
\text { and focus groups to find out the extent to which their undertakings } \\
\text { produce valuable societal change or not. } \\
\text { 3.1.2. The social enterprise sets key performance indicators to } \\
\text { determine the impact of its innovativeness pursuit, such examples } \\
\text { being the number of individuals receiving vocational trainings, or } \\
\text { continuing their education, or becoming employed, the amount of } \\
\text { employment support received by people facing poverty to escape } \\
\text { this situation. }\end{array}$ \\
\hline $\begin{array}{l}3.2 \\
\mathrm{bac}\end{array}$ & $\begin{array}{l}\text { 3.2.1. Innovation objectives are clearly set by the social } \\
\text { entrepreneur, who is the leader of innovation processes within the } \\
\text { organization, and carefully disseminates them to the social } \\
\text { enterprises' members at all levels. } \\
\text { 3.2.2. There is a learning by doing methodology that is internally } \\
\text { implemented and which enables the innovativeness of the social } \\
\text { enterprise by reshaping the defined objectives based on internal } \\
\text { consulting processes. }\end{array}$ \\
\hline
\end{tabular}




\section{Conclusion}

Taking the necessary steps towards innovativeness is mandatory for providing efficient resolutions to the modern world issues, either in the business sphere or the societal one. As a dynamic and fluid process, innovation links society actors in an attempt towards reshaping the current static approach and attaining a structure based on knowledge sharing and multistakeholder partnerships. In these conditions, innovation capabilities must be fostered and properly assessed, otherwise the innovation pursuit generates a weak impact and cannot be extended in time. In the case of traditional enterprises, literature indicates many frameworks by which these capabilities can be evaluated, but as regards social enterprises, and especially the ones from Romania, there is a scarce conceptualization. There is a visible need for more research in this respect, especially given the rough present standing of Romania and its confrontation with economic and societal deficiencies: poverty, social exclusion and reduced public support.

The paper aims to identify a model for evaluating the innovation capabilities of social enterprises operating in Romania, based on good practices of three Horizon 2020 social innovation programs. The newly generated model firstly places emphasis on the collaborative social networks of the social enterprise, meaning the organizational competency to attract and integrate public and private linkages with community actors. A secondary dimension referred to is the innovation proactivity, which reflects on the orientation towards the beneficiaries and the formulation of an innovation approach in correlation with extrinsic conditions. Finally, the model encompasses the social innovation strategy and assesses the social enterprise's usage of key performance indicators, tools and innovation objectives.

The research limitation was constituted by the formulation of the evaluation model solely on the basis of the narrow existing literature and the three Horizon 2020 projects, hence further exploratory efforts must be employed to provide an extensive perspective. As for the utility of the findings of the paper, they may be employed by social entrepreneurs in order to build a sustainable and coherent knowledge-oriented innovation approach adapted to their beneficiaries' needs and other external requirements.

\section{References}

Andries, P., Daou, A., \& Verheyden, L. (2019). Innovation as a vehicle for improving socially vulnerable groups' access to basic provisions: A research note on the development of a questionnaire module. Research Policy, 48(1), 281-288.

Akcali, B.Y., \& Sismanoglu, E. (2015). Innovation and the Effect of Research and Development (R\&D) Expenditure on Growth in Some Developing and Developed Countries. Procedia Social and Behavioral Sciences, 195, 768-775.

Ashoka (2019). Ashoka Romania impact report 2017-2018. Retrieved from http://ashokacee.org/romania/en/2019/05/31/ashoka-romania-impact-report-2017-2018-2/.

Avelino, F., Wittmayer, J.M., Pel, B., Weaver, P., Dumitru, A., Haxeltine, A., Kemp, R., Jørgensen, M.S., Bauler, T., Ruijsink, S., \& O’Riordan, T. (2019). Transformative social innovation and (dis)empowerment. Technological Forecasting and Social Change, 145, 195-206.

Bellini, F., Dulskaia, I., Savastano, M., \& D’Ascenzo, F. (2019). Business model innovation for sustainable urban modibility in small and medium-sized European cities. Management \& Marketing - Challenges for the Knowledge Economy, 14(3), 166-277.

Benaim, A. (2015). Innovation Capabilities - Measurement, Assessment and Development. Retrieved from https://portal.research.lu.se/portal/files/5726507/7370550.pdf. 
Björkdahl, J., \& Börjesson, S. (2012). Assessing firm capabilities for innovation. International Journal Knowledge Management Studies, 5(1/2), 171-184.

Cantillon, B., Marchal, S., \& Luigjes - Herman, C. (2015). Decent incomes for the poor: which role for Europe?. Retrieved from http://improve-research.eu/?page id=1928.

European Commission (2014). Horizon 2020 in brief - The EU Framework Programme for Research and Innovation. Retrieved from https://ec.europa.eu/programmes/ horizon2020/sites/horizon2020/files/H2020 inBrief EN FinalBAT.pdf.

PICBE $\mid 100$

Except Project (2019). About the Except Project. Retrieved from http://www.exceptproject.eu/about-the-project/.

Fred-Ojala, A., Sidhu, I., Johnsson, C., \& Suoranta, M. (2018). The Berkeley Innovation Index: A Quantitative Approach to Measure, Track and Forecast Innovation Capability within Individuals and Organizations. In Kim, K.J., Kim, H. (Eds.). Mobile and Wireless Technology 2018: International Conference on Mobile and Wireless Technology (ICMWT 2018) (pp. 311-320). Springer, Singapore.

Grillo, C., Ferreira, F.A.F., Marques, C.S.E., \& Ferreira, J. (2018). A knowledge-based innovation assessment system for small- and medium-sized enterprises: adding value with cognitive mapping and MCDA. Journal of Knowledge Management, 22(3), 696-718.

Haryani, S., \& Gupta, V.B. (2016). Factors affecting innovation capability of Indian software firms (with special reference to Indore city). International Research Journal of Engineering and Technology (IRJET), 3(12), 1213-1219.

ImPRovE (2012). Welcome to ImPRovE. Retrieved from http://improve-research.eu/.

Jiménez-Jiménez, D., \& Sanz-Valle, R. (2011). Innovation, organizational learning, and performance. Journal of Business Research, 64, 408-417.

Kocziszky, G., \& Somosi, M.V. (2016). Generating social innovation with knowledge engineering. Procedia - Social and Behavioral Sciences, 223, 167-174.

Leventi, C., Sutherland, H., \& Tasseva, I.V.(2016). Improving poverty reduction in Europe: what works (best) where?. Retrieved from http://improve-research.eu/?page_id=37.

MacDonald, A., Clarke, A., \& Huang, L. (2019). Multi-stakeholder Partnerships for Sustainability: Designing DecisionMaking Processes for Partnership Capacity. Journal of Business Ethics, 160(3), 409-426.

Matuleviciene, M., \& Stravinskiene, J. (2015). The Importance of Stakeholders for Corporate Reputation. Inzinerine Ekonomika-Engineering Economics, 26(1), 75-83.

Mitra-Crisan, C., Dabija, D.-C., \& Dinu, V. (2015). Social Entrepreneurship in Romania: Significance and Models. Montenegrin Journal of Economics, 11(2), 65-77.

(Moh'd Taisir) Masa'deh, R., Gharaibeh, A.H., Tarhini, A., \& Obeidat, B.Y. (2015). Knowledge Sharing Capability: A Literature Review. Conference Proceedings (COES\&RJ-CP), 2(5), $1-16$.

Mosher-Williams, R. (2006). Research on social entrepreneurship: understanding and contributing to an emerging field. Retrieved from https://cdn.ymaws.com/arnova.siteym.com/resource/resmgr/Publications/ARNOVA_Research_on_Social_En.pdf.

Oliveira, S.R.M., \& Trento, S. (2018). Borderless Innovation: Innovation Capā̄ility Assessment on Business Incubators Performance using Resources, Leadership and Capability: An Investigation in Business Incubators from Chile, Italy and Israel. European Journal of Scientific Research, 151(2), 143-159.

Paixão Garcez, M., Sbragia, R., \& Kruglianskas, I. (2014). Factors for selecting partners in innovation projects - Evidences from alliances in the Brazilian petrochemical leader. $R A I$ - Revista de Administração e Inovação, 11(2), 241-272.

Pantea, M.- C. (2018). Youth unemployment policies in Romania. Retrieved from http://www.except-project.eu/files/filemanager/files/ WP45_Youth_employment_policies_in_Romania.pdf.

Păunescu, C., Popescū, M.C., \& Duennweber, M. (2018). Factors Determining Desirability of Entrepreneurship in Romania. Sustainability, 10(11), 1-22. 
Pollex, J., \& Lenschow, A. (2018). Surrendering to growth? The European Union's goals for research and technology in the Horizon 2020 framework. Journal of Cleaner Production, 197, 1863-1871.

Poon, D. (2011). The Emergence and Development of Social Enterprise Sectors. Retrieved from https://repository.upenn.edu/cgi/viewcontent.cgi?article $=1010 \&$ context $=$ sire.

Preda, G. (2013). The influence of entrepreneurial orientation and market-based organizational learning on the firm's strategic innovation capability. Management \& Marketing

PICBE | 101 Challenges for the Knowledge Society, 8(4), 607-622.

Purwanggono, B., \& Amalia, A.N. (2019). Modified assessment tools for measuring innovativeness level of companies. Production \& Manufacturing, 6(1), 1-12.

Rådesjö, D., \& Sandström, A. (2013). Assessing Capabilities for Innovation: The Case of Statkraft AS. Retrieved from https://pdfs.semanticscholar.org/ a046/88bc6b5e66e0e6dcbf4aa1c6f8f5bd851552.pdf.

Reficco, E., Gutiérrez, R., Jaén, M.H., \& Auletta, N. (2018). Collaboration mechanisms for sustainable innovation. Journal of Cleaner Production, 203, 1170-1186.

Rodriguez, L., Diaz, J., Garbajosa, J., Perez, J., \& Yagüe, A. (2014). A Framework for Positioning and Assessing Innovation Capability from an Organizational Perspective. Proceedings of the 2014 47th Hawaii International Conference on System Sciences, 35643573.

Rumanti, A. A., Samadhi, T.M.A.A, Wiratmadja, I.I., \& Sunaryo, I.(2018). A Systematic Literature Review on Knowledge Sharing for Innovation: Empirical Study Approach. Proceedings of $20185^{\text {th }}$ International Conference on Industrial Engineering and Applications, 504-509.

SIMRA (2019). Work packages. Retrieved from http://www.simra-h2020.eu/ index.php/work-packages/.

Schuitmaker, T.J. (2012).Identifying and unravelling persistent problems. Technological Forecasting \& Social Change, 79, 1021-1031.

Testi, E., Biggeri, M., Bellucci, M., During, R., \& Persson, H. T.R. (2019).An introduction to social entrepreneurship in Europe. In Biggeri, M., Testi, E., Bellucci, M., During, R., Persson, H.T.R. (Eds.). Social entrepreneurship and social innovation (pp. 1-12). Routledge, London and New York.

Wallin, J., Larsson, A., Isaksson, O., \& Larsson, T. (2011). Measuring Innovation Capability Assessing Collaborative Performance in Product-Service System Innovation. In Hesselbach, J., Herrmann, C. (Eds.). Functional Thinking for Value Creation (pp. 207212). Springer: Berlin, Heidelberg. 